\title{
ACESSIBILIDADE NA FORMAÇÃO DE PROFESSORES- AUTORES DE MATERIAL DIDÁTICO-DIGITAL PARA A EAD: UM TRABALHO COM DEFICIENTES VISUAIS
}

\author{
DÉBORA LIBERATO ARRUDA HISSA ${ }^{1}$
}

Programa de Pós-graduação em Linguística Aplicada, Universidade Estadual do Ceará Avenida Luciano Carneiro, 345 - 60410-690 - Fortaleza - CE - Brasil

debarruda@gmail.com

Resumo. Tomando como base a perspectiva dialógica da linguagem estabelecida por Bakhtin (2011), este estudo se baseia na escrita colaborativa para descrever uma experiência de ensino concernente a um curso de formação de professores autores de material didático-digital para a Educação a Distância (EaD). O objetivo do curso foi instruir professores, alguns dos quais com deficiência visual, para produzirem material nos moldes da linguagem para a EaD. Com o auxílio de ferramentas de acessibilidade, na formação, os professores produziram material didático-digital para o curso de Pós-graduação em Orientação e Mobilidade (OM) na modalidade semipresencial. Participaram da formação 10 professores (cinco deles com deficiência visual). Discutimos na formação a ideia de dialogismo e responsividade orientados na perspectiva de que qualquer enunciado, seja ele elaborado de forma individual ou colaborativa, só se constitui como tal na interação com os outros enunciados presentes no contexto sócio-histórico real em que ele acontece e é realizado. A partir de quatro temáticas principais (1) EaD: conceitos, legislação, características e modelos; (2) Planejamento; (3) Produção de conteúdo impressos; e (4) Produção de conteúdo digital, estruturamos as aulas do curso de formação. Em cada encontro, foram feitas adaptações no curso para que os professores com deficiência visual pudessem participar das discussões e do processo de ensino-aprendizagem de forma eficaz. Ao final do curso, vimos que as identidades dos professores se organizam no processo de comunicação interdiscursiva de caráter intrinsecamente dialógico e que o material didático-digital é produzido de forma colaborativa a partir das atitudes responsivas de cada sujeito envolvido no processo de produção.

Palavras-chave: Educação a Distância; formação de professores-autores com deficiência visual; produção de material didático digital.

\begin{abstract}
Based on the dialogical perspective of language established by Bakhtin (2011), this study takes the concept of collaborative writing to describe a teaching experience that occurs in a training course for teachers who are authors of didactic-digital material for Distance Education (EaD). The objective of the course was to instruct teachers (some of them visually impaired) to produce material in the language format for EaD. With the aid
\end{abstract}

\footnotetext{
${ }^{1}$ Doutora em Linguística Aplicada pela Universidade Estadual do Ceará.
} 
of accessibility tools, during the course, teachers produced didactic-digital material for the post-graduation course in Orientation and Mobility (OM) in the blended mode. Ten teachers (five of them with visual impairment) participated in the course. We discussed the concepts of dialogism and responsiveness oriented in the perspective that any statement, be it elaborated in an individual or collaborative way, is only constituted as such in the interaction with the other statements present in the real socio-historical context in which it happens and is accomplished. From four main themes (1) EaD: concepts, legislation, characteristics and models; (2) Planning; (3) Production of printed content; and (4) Production of digital content, we structured the lessons of the training course. At each meeting, adaptations were made in the course so that teachers with visual impairment could participate in the discussions and in the teaching-learning process in an effective way. At the end of the course, we saw that the identities of teachers are organized in the process of interdiscursive communication of an intrinsically dialogical nature and that the didactic-digital material is produced in a collaborative way from the responsive attitudes of each subject involved in the production process.

Keywords. Distance Education; training author teachers with visual disabilities; production of electronic didactic material.

\section{Introdução}

A questão da acessibilidade nos portais e sites informacionais/educacionais é discutida há mais de uma década em todo o mundo. Desde 2003, a União Europeia adotou o termo e-acessibilidade para se referir à temática na web e a maioria dos países integrantes criaram uma legislação para assegurar acessibilidade nos sites dos governos europeus. No Brasil, na Lei $n^{\circ} 10.098$, o Decreto ${ }^{\circ}$ 5.296/2004, em seu artigo 47, trata especificamente da obrigatoriedade da acessibilidade nos portais e sítios eletrônicos da administração pública na rede mundial de computadores (internet), a fim de garantir o pleno acesso às informações para pessoas portadoras de deficiência visual (BRASIL, 2013).

Neste artigo, pretendemos discutir a acessibilidade nos materiais didático-digitais (MDD) para a Educação a Distância $(\mathrm{EaD})$ como uma característica necessária para os cursos que trabalham com alunos com deficiência visual como forma de assegurar que todos tenham acesso ao conteúdo das disciplinas em iguais condições para que os alunos não se vejam excludentes entre si. Mostraremos uma experiência com a adaptação de material didático-digital, com base nos preceitos da acessibilidade, para um grupo de professores deficientes visuais que produzirão material didático-digital para o Curso de Especialização em Orientação e Mobilidade (OM) ofertado pelo Instituto Federal de Educação, Ciência e Tecnologia do Ceará (IFCE). Nosso objetivo é compartilhar uma formação de professores em que foram utilizados alguns recursos disponíveis pelas novas tecnologias para garantir a acessibilidade na EaD. Queremos com isso melhorar os processos de aquisição do conhecimento e de aprendizagem multissensorial; estimular o desenvolvimento cognitivo; fomentar a aprendizagem colaborativa, a autonomia de habilidades sociocomunicativas; e satisfazer as necessidades educacionais de pessoas 
com deficiência visual.

Organizamos nossas reflexões em torno da noção de dialogismo - que se fundamenta na premissa de que o discurso é constituído na e pela interação com os outros discursos, e responsividade - que se refere à premissa de que todo enunciado se organiza como resposta a outros enunciados, reais ou virtuais, em circulação no contexto discursivo. Tomamos também a ideia de que enunciado é a unidade de comunicação discursiva em que as relações dialógicas se manifestam. Compreendemos, pois, essas relações como um processo discursivo entre sujeitos que, ao se dirigirem a um determinado objeto de sentido, encontram-se, inevitavelmente, com outros discursos também dirigidos para o mesmo objeto de sentido. Desse modo, as relações dialógicas são a forma de realização do dialogismo e da responsividade que, dentro do discurso, se dirigem ao mesmo tempo para o seu objeto de sentido e para o discurso do outro. Essa é uma das premissas norteadoras de nosso estudo sobre a acessibilidade na formação de professores autores de material didático-digital (MDD).

A ideia de dialogismo se apresenta nos textos de Bakhtin (2011) quando ele assume o posicionamento de que toda enunciação se dirige ao outro, a fim de orientar a compreensão e a resposta, o consenso ou o dissenso. Bakhtin compreenderá a linguagem não como uma mera atualização e utilização de códigos arbitrários ou repositórios discursivos existentes socialmente, e sim como uma complexa situação social em que cada enunciado se coloca de um modo muito singular e único, sempre diverso em um mundo repleto de outros enunciados com os quais ele se conecta, se baseia e se posiciona. Cada enunciado é, portanto, uma reposta, única e singular, a outro enunciado.

Bakhtin, em seus textos, explica que a linguagem emerge como interação, e assim surge a noção de diálogo, já que qualquer interação verbal ocorre na forma de intercâmbio de enunciados. A partir dessa premissa, entendemos que, para que haja acessibilidade nos MDDs, os materiais devem ser produzidos de forma colaborativa e orientada para ampliar as possibilidades de os alunos que estudam em EaD terem acesso ao conteúdo didático. Logo é necessária uma apresentação e estruturação cuidadosa do material, estudada e adaptada ao contexto de ensino para garantir que os alunos consigam estudar pela web de forma autônoma e sem a necessidade de intervenção de outras pessoas.

O material didático-digital para $\mathrm{EaD}$ configura-se como conteúdo elaborado e desenvolvido nas variadas mídias, de acordo com o modelo pedagógico do curso, buscando atender de forma diversificada a seu público-alvo. Para Guedes (2010), a produção do material didático para cursos a distância é um dos principais desafios dessa modalidade educacional, em razão da diversidade das mídias em que é veiculado no momento contemporâneo: on-line e off-line, impresso e digital, áudio e vídeo, imagem e texto etc.

Os materiais impressos são recursos que utilizam o papel como suporte de comunicação. Em cursos a distância, esse material pode assumir forma e conteúdo que se ajustam à concepção pedagógica do curso: manual, livro-texto, guia de estudo, texto autoinstrucional, publicação técnica. O material online, por sua vez, é considerado uma mídia eletrônica e tem o potencial de promover uma maior interatividade entre aprendiz e conteúdo, já que conta com recursos multimodais (como imagem, conteúdo audiovisual, animações etc.), bem como a utilização de links que conferem hipertextualidade ao 
material produzido que será disponibilizado aos alunos no Ambiente Virtual de Aprendizagem $^{2}$ (AVA) como mais um recurso que eles podem utilizar para aprofundar os conhecimentos nas temáticas estudadas em cada disciplina.

Almenara (2011) descreve dois diferentes princípios para se considerar a produção de materiais didáticos para a EaD: pedagógico-narrativos, que se referem à escrita do conteúdo; e estético-técnicos, que se referem à inserção dos elementos multimodais no conteúdo verbal já produzido. Para este autor, a produção de uma web-aula adequada dependerá em maior medida dos princípios pedagógico-narrativos que, por sua vez, dependem da concepção contextual e científica que se tem em conta na hora da produção da web-aula.

Almenara salienta que a produção de materiais para o ambiente virtual de aprendizagem (AVA) é totalmente diferente da criação de textos planos, isto é, de textos criados para o meio impresso. Para ele, a web-aula deve incluir diferentes elementos: a exposição dos objetivos que o professor pretende que o aluno alcance; o esquema dos conteúdos a desenvolver na web-aula (uma espécie de sumário); a existência de uma introdução e apresentação de recomendações para o estudo; a proposta de atividades que os alunos devem realizar; a existência de elementos de aprofundamento e extensão dos conteúdos oferecidos; o sumário das ideias mais significativas desenvolvidas na webaula; e o resumo dos aspectos mais importantes tratados. No entanto, acreditamos que todos estes aspectos parecem mais uma descrição das etapas de construção de um texto didático impresso do que de uma web-aula como a concebemos. Não há menção, pelo autor, das potencialidades que esse gênero propicia, tais como maior extensão de conteúdo devido à possibilidade de navegação em hiperlinks, por exemplo.

Assim, cientes da demanda de produção de material didático-digital exigida pelos inúmeros cursos na modalidade a distância em vigência no Brasil, contextualizamos nosso estudo no trabalho feito no IFCE com a formação de professores autores desses materiais. Vimos que, na maioria dos cursos a distância do IFCE, o aluno tem acesso a materiais didáticos, produzidos pela própria instituição, tanto no formato impresso quanto no formato digital (web-aulas). Para a produção dos conteúdos, os professores autores são convidados pela equipe multidisciplinar de produção de material didático-digital e passam, inicialmente, por uma formação. Essa formação é ministrada por professores da área de Linguística a partir de uma perspectiva bakhtiniana em que se têm como foco aspectos constitutivos da linguagem, como o dialogismo e a responsividade.

No contexto específico de nosso estudo, analisamos um curso de formação de professores-autores ${ }^{3}$ promovido pelo IFCE, cuja produção de material didático-digital foi voltada para o Curso de Pós-graduação em Orientação e Mobilidade - OM, na modalidade semipresencial (360h). O curso de formação foi ofertado de forma semipresencial, ou seja, os professores teriam momentos presenciais em sala de aula com os formadores da área de Linguística e outros momentos a distância com tutores que deram continuidade à formação no AVA. A formação foi dividida em quatro aulas

\footnotetext{
${ }^{2} \mathrm{O}$ Ambiente Virtual de Aprendizagem analisado para o contexto dessa pesquisa foi o Moodle.

${ }^{3}$ No IFCE, chama-se professor-conteudista aquele que escreve o conteúdo específico informacional da disciplina de um curso em EaD. Em muitas instituições de ensino que trabalham com EaD, esse professor é conhecido como professor-autor. Por isso, no título deste trabalho, preferimos dar um enfoque mais global ao termo, a fim de facilitar o reconhecimento do assunto tratado neste texto.
} 
(elaboradas pela equipe de produção de material didático-digital do IFCE) e teve a duração de 48h/a - quatro aulas a distância com 10h/a cada -, e dois encontros presenciais com $4 \mathrm{~h} / \mathrm{a}$ cada.

As aulas foram postadas no Ambiente Virtual de Aprendizagem (AVA) Moodle no formato de web-aulas e em arquivos na extensão .doc e .ppt. Os temas de cada aula foram: Educação a distância, conceitos, legislação, características e modelos; Planejamento do produção de material didático; Produção de conteúdo I (material impresso); Produção de conteúdo II (e-book). Todos os conteúdos foram adaptados para o acesso de pessoas com deficiência visual.

Os participantes do curso foram 10 professores (5 deles cegos), cuja formação era variada: mestres em educação física, em educação especial e em biotecnologia; especialistas em psicomotricidade, em terapia ocupacional e em orientação e mobilidade. Esses professores já possuíam experiência docente de cursos em OM na modalidade presencial, porém nunca tinham tido contato com o ensino na modalidade a distância. Isso representou um desafio maior no curso, pois era necessário levar em consideração a familiaridade de todos os professores de forma geral no uso de ferramentas digitais de comunicação e informação, bem como as necessidades específicas de acesso dos professores com deficiência visual na plataforma Moodle, nos conteúdos elaborados e nas informações e comunicados do curso.

Neste artigo, mostraremos a estrutura do curso, a organização das aulas e os enfoques pedagógico e linguístico que perpassaram o curso, com o objetivo de divulgar o trabalho de formação de professores-autores que vem sendo desenvolvido no IFCE e ampliar as discussões acerca da produção material didático em EaD para professores com deficiência visual. Também serão descritas informações sobre o processo de adaptação dos materiais didáticos para pessoas com deficiência visual. Dividimos o artigo em 3 tópicos teóricos: no primeiro, apresentaremos o conteúdo de cada uma das 4 aulas do curso de formação, no segundo, entenderemos a dinâmica dos 2 encontros presenciais da formação e no terceiro discutiremos o processo de adaptação do curso para pessoas com deficiência visual. As bases teóricas utilizadas (BAKHTIN, 2011; CHEVALLARD, 1991) para a formação de professores-autores.

\section{Construção da autoria e identidade nos materiais didáticos-digitais}

A autoria de um enunciado (em especial o enunciado escrito) indica uma indicando uma inter-relação do eu com o outro que embasa o diálogo e sustenta a alteridade e o dialogismo. Isso significa dizer que o sujeito enunciativo reflete, em seu discurso, a voz do outro, por isso a presença do outro (alteridade) vai construindo a sua identidade (do sujeito), ou seja, vai construindo uma identidade heterogênea. Dessa forma, a alteridade é um princípio importante se queremos refletir sobre identidade e autoria, especialmente nos materiais didáticos-digitais produzidos de forma colaborativa para a EaD.

Podemos dizer que a identidade de um sujeito, com base em Bakhtin (2011), é um fenômeno social que resulta de complexas relações do "eu" consigo mesmo e com os "outros". Esse caráter social da identidade se converte em um processo de relações 
ideológicas, culturais e históricas dentro de um espaço de interesse, posição, hierarquia e negociação de sentidos.

Bakhtin (2011, p. 136) usa o conceito de apropriação para explicar o processo de interiorização a partir de uma visão dialógica e da ideia de esforço que o sujeito tem para dominar o significado dos discursos do outro e, para desses discursos, construir o seu próprio discurso, isto é, para passar definitivamente da propriedade coletiva para a propriedade privada no que se refere ao uso da linguagem. Para Bakhtin, a linguagem só se converterá em uma linguagem própria quando o sujeito introduz sua própria intenção, seu próprio acento, quando ele se apropria da palavra, adaptando-a para sua intenção semântica e expressiva. Antes do movimento de apropriação, a palavra não existe em uma linguagem neutra e impessoal, mas sim na boca de outras pessoas, nos contextos de outras pessoas e será daí que se deve tomar a palavra, apropriando-se dela. Por isso, a linguagem não pode ser vista como um meio neutro que passa simplesmente a formar parte das intenções do sujeito.

Essa tarefa de apropriação não é fácil, visto que a linguagem está superpovoada de intenções que requerem um esforço axiológico de expropriação para que os significados dos outros passem a ser parte das intenções pessoais do sujeito, a fim de serem usados intencionalmente em contextos diversos, gerando novos significados. Seria então nesse esforço de expropriação que poderíamos centrar o conceito de autoria, principalmente no que concerne à autoria em textos escritos, foco deste trabalho. A autoria seria o esforço dos sujeitos em se diferenciar de outras vozes, de ter singularidade e ao mesmo tempo dialogar com elas. Bazerman (2004), em se tratando de textos escritos, entra na discussão sobre identidade do sujeito quando afirma que ela - a identidade - se constrói discursivamente, por isso a voz nos textos escritos não deveria ser estudada somente através das análises textuais, mas também à luz de como ela - a voz - é interpretada e utilizada, dando-se ênfase maior à intencionalidade do autor, aquela que o leva a tomar uma determinada posição.

Em se tratando de construção da identidade no discurso acadêmico, Spivey (1997) defende que a identidade do sujeito se dá a partir de uma ampla rede de textos interrelacionados, na qual os escritores constroem sua identidade de autor mediante as conexões dialógicas que estabelecem com os textos de outros autores. Para Spivey, o processo de construção da identidade de um autor é um processo individual que depende de conexões que o escritor estabelece inclusive com os leitores, os quais irão interpretar os textos do autor, citá-los, avaliá-los, criticá-los etc. Dessa maneira, o escritor se identifica a si mesmo e, ao mesmo tempo, aos outros sujeitos identificam a autoria desse escritor entre aquelas que estão no território textual de escrita acadêmica. Essa "intertextualidade" tem uma função importante dentro dessa perspectiva de construção da autoria, tanto para compreender como para estudar a identidade do autor.

Furlanetto (2008) discute a identidade no tocante aos gêneros discursivos, a fim de desenvolvê-la e reconhecê-la a partir do querer-dizer do sujeito. Para a autora, existe no discurso a necessidade enunciativa de iterar (repetir, retornar à memória do dizer) e alterar (produzir enunciativamente para obter um efeito de atualidade) e dessa necessidade surge a identidade dentro de uma determinada comunidade discursiva, isto é, surge o efeito de autoria. Assim, produzir um texto significa, nas palavras de Furlanetto, dispersar e controlar a dispersão, num movimento enunciativo de busca por unidade, por fechamento. 
Vimos que, para conceituar identidade na perspectiva da autoria nos enunciados, temos que partir da ideia de identidade como um constructo social, cultural e historicamente situado, cuja dimensão individual está relacionada com o fato de que a autoria (a identidade do autor) se manifestará através de determinados usos estratégicos da linguagem vinculados ao processo de enunciação e de tomada de posição no discurso. A dimensão social e situada tem a ver tanto com a consciência do autor sobre o poder de suas palavras nos enunciados para representá-lo - como membro de uma comunidade discursiva - quanto com a necessidade de ajustar o próprio discurso em função dos outros sujeitos.

Essa consciência do autor se dá quando o sujeito revela uma condição de responsabilidade, já que os enunciados são uma construção única e específica que afetam aqueles que se relacionam com eles. Essa ação de completude do sujeito no outro, em que ocorre uma responsabilidade do ato, nos interessa para marcarmos uma posição sobre o que compreendemos acerca de identidade e autoria. A responsabilidade do ato marcará a constituição do sujeito, o qual se desenvolve a partir de sua relação com os outros, constituindo-se uma unidade dinâmica, temporal, histórica e discursiva.

\section{Produção didática colaborativa: bases teóricas}

As ideias de dialogismo e alteridade voltam à tona para se estabelecer como aspectos de uma produção didática colaborativa. Para Araújo et al (2015), perguntas reflexivas como para quem se escreve e para que se escreve podem determinar como será um escrito de cunho didático especialmente quando pensamos no papel do outro (para quem se escreve/fala) na linguagem.

Sempre que um professor textualiza o conteúdo didático para um texto escrito a partir de estratégias didáticas de interação escrita, na forma de material didático-digital, ele tem um projeto de dizer que se dirige a alguém. Esse projeto de dizer apresenta objetivo(s) específico(s) e acontece em uma determinada situação comunicativa. Já sabemos da importância desse alguém a quem se dirige a interação verbal, em outras palavras, da importância do outro, no dizer de Bakhtin (2011). Vimos que, na perspectiva bakhtiniana, qualquer enunciado (texto ou frase, por exemplo) se organiza em função do outro. Isso se dá porque é a partir da convivência com o outro que o ser humano se constitui como tal [ser humano]. Essa convivência necessária é o que dá origem a um dos princípios que são constitutivos da própria linguagem: o dialogismo.

Araújo et al (2015) explicam que, se observamos algumas atitudes responsivas que temos diante de um texto, perceberemos que podemos concordar, discordar, achar interessante, irrelevante; podemos relacioná-lo a outros conhecimentos que já temos, podemos pensar sobre exemplos de usos da linguagem a partir dele, entre outras atitudes. Todas essas respostas ativas são atitudes responsivas, sejam elas verbais ou não. Por isso, no caso da produção colaborativa de material didático-digital, deve-se também esperar atitudes responsivas dos professores em relação ao que eles produziram. Dessa forma, produzir colaborativamente é uma forma de textualizar pensando que a principal atitude responsiva esperada deva ser a compreensão ativa pelo aluno que terá acesso ao material 
didático. Na construção da compreensão, além daquilo que está no texto e que é composto de vozes de outros textos e das escolhas feitas pelo autor, entram também os saberes já construídos pelo aluno, seu lugar social, suas expectativas.

Para trabalharmos estes aspectos, o curso de formação de professores-autores foi dividido em quatro aulas a distância, com 10h/a cada. As aulas foram disponibilizadas no AVA do IFCE em arquivos na extensão .doc e no formato digital online (web-aulas). A cada aula, foram discutidos assuntos relacionados à produção de material didático-digital. Todos os professores fizeram o cadastro no ambiente, por meio de um login e de uma senha, para terem acesso às web-aulas do curso de formação e as atividades referentes ao curso. As temáticas das aulas de formação dos professores-autores foram "Educação a distância: conceitos, legislação, características e modelos"; "Planejamento: fases da produção do conteúdo didático-digital"; "Produção de conteúdo: as características da tarefa de escrita de material didático-digital"; e "Desenvolvimento da escrita colaborativa: interação entre os sujeitos".

Em todas as aulas, foi salientado, por partes dos ministrantes do curso, que o perfil dos alunos - para os quais serão produzidas as aulas -, as regras e os objetivos da instituição (IFCE) devem ser considerados na escolha e na produção do conteúdo por parte dos autores. Também foi salientado que as atividades produzidas no material didático-digital devem ser voltadas para a aprendizagem do aluno adulto, logo devem ter relação com a reflexão e a ação dele no curso de Orientação e Mobilidade. No curso, foi dada ênfase à noção de dialogismo e responsividade (BAKHTIN, 2011), ao planejamento do Plano de Unidade Didática (PUD) e aos aspectos interacionais do texto didático a ser escrito pelo professor. A seguir, veremos o conteúdo de cada aula.

\subsection{A incorporação do texto para um novo espaço de interação}

Dentre as características de uma produção didático-digital, uma em especial tem bastante relevância para este estudo. Trata-se do modo de produção desse gênero, cuja colaboração entre sujeitos especializados é a base do processo de escrita. Sabemos que a escrita colaborativa se trata de um processo de produção textual que se dá a partir da colaboração de diferentes sujeitos que juntos produzem o mesmo texto. Esses sujeitos cooperam na produção escrita por meio de estratégias de interação (recados escritos, discussão presencial, revisões e correções no texto, etc.) com intuito de construir colaborativamente o texto.

No que se refere à escrita colaborativa, Murray (1992) a divide em dois tipos segundo a interação que a compõe: interação escrita (ocorre no papel) e interação oral (nos diálogos). Nessa escrita, os comentários feitos em ambas interações incidem tanto sobre o conteúdo (de forma global) como sobre a linguagem (aspectos linguísticos, como léxico, sintaxe, por exemplo). Para a autora, uma escrita colaborativa só alcançará sucesso se o grupo de autores tiver um objetivo em comum e se houver uma eficiente negociação de sentidos dentro de um grupo com diferentes conhecimentos no que diz respeito ao conteúdo do texto, ao estilo, às habilidades comunicativas. Murray afirma também que a negociação de sentidos pode ser construída através de uma atividade que chamou de information gap (uma espécie de "informação que falta"). Nessa negociação, os sujeitos que participam da produção colaborativa em grupo, como não possuem todas as 
informações de que necessitam para a escrita do texto, devem socializar seu escrito com os demais colegas de forma a produzirem colaborativamente o texto.

Também discutindo a escrita colaborativa, Sanchéz (2009) explica que os sujeitos participantes do processo devem compartilhar a responsabilidade de produção do texto, no que se refere à estrutura, ao conteúdo e à linguagem. $\mathrm{O}$ autor salienta que uma escrita colaborativa vai mais além de uma revisão entre pares (atividade bastante comum quando se trata de estudos sobre escrita colaborativa), pois favorece o pensamento reflexivo (sobretudo se os participantes usam estratégias para defender ou explicar melhor suas ideias); a abordagem de questões relativas ao discurso (e não apenas à materialidade do texto em seus aspectos formais, por exemplo); e o desenvolvimento da linguagem.

Por isso a primeira aula, intitulada "Educação a distância: conceitos, legislação, características e modelos", teve como abordagem principal as orientações básicas e os principais conceitos relacionados à Educação a Distância $(\mathrm{EaD})$. A aula foi composta de quatro tópicos, cujos conteúdos são importantes para a compreensão das características e do funcionamento da $\mathrm{EaD}$ e para a elaboração e preparação de materiais educacionais, impressos e digitais destinados ao Curso de Pós-graduação em Orientação e Mobilidade - OM, na modalidade semipresencial. Os objetivos da primeira aula do curso foram fazer com que os alunos, 10 professores, compreendessem o conceito de Educação a Distância, de distância transacional e sua relação com autonomia; conhecessem a evolução tecnopedagógica em Educação a Distância; estabelecessem as diferenças e semelhanças entre educação presencial e educação a distância; e conhecessem o modelo pedagógico de EaD adotado no IFCE.

Nesta aula, focou-se também, entre outras pautas, no fato de que, em $\mathrm{EaD}$, além de o aluno dispor da internet para a realização de suas atividades, normalmente lhe é fornecido material didático em mídia impressa e em mídia digital (seja online ou off-line). Na maioria dos materiais, há uma preocupação, por parte de quem os elabora, em deixálos ricos em recursos tecno-pedagógicos, de modo que a informação seja compartilhada de forma clara ao estudante. Tomou-se como fundamentação, dentre outros autores, Rodríguez de las Heras (2002). O autor afirma que é preciso seguir duas novas regras que dizem respeito à incorporação do texto para um novo espaço de interação como o AVA: $1^{\circ}$ ) não transferir para a tela atividades que se realizem em outros meios sem aplicar mudanças severas que as reajustem para o novo suporte; e $2^{\circ}$ ) explorar o que o AVA traz de novidade, de recursos, de ferramentas e descobrir aquilo que os outros suportes de texto não podem oferecer.

A aula 1 continha duas atividades: um fórum e uma tarefa. $\mathrm{O}$ fórum trazia um vídeo do Jornal Bom-dia Brasil que abordavam aspectos diversos da $\mathrm{EaD}$ como modalidade de ensino. Os cursistas deveriam assistir ao vídeo e participar do fórum respondendo a três questionamentos. Tais questões objetivavam uma tomada de consciência por parte do professor-autor a respeito do perfil de aluno para o qual estava escrevendo, bem como das particularidades da modalidade de ensino a distância e da escrita para essa modalidade. A seguir, apresentaremos o enunciado do fórum no AVA, bem como exemplos de participação dos alunos (professores autores). 
Fórum - EaD: caracteristicas, perfil do aluno e inquietações

Como professor conteudista, você é um dos responsáveis pelo êxito do Curso de Especialização em Orientaçầo e Mobilidade, na modatidade a distáncia. Nesta aula, vimos que em EaD cada um dos atores (professores, equipe pedagógica, equipe técnica e alunos) precisa ter caracteristicas especificas e conhecer bem essa modalidade de ensino.

Assista ao video Matéria sobre EaD (exibido no Bom Dia Brasil no dia 11 de fevereiro de 2011).

Agora, faça o que seque:

1. Diga que caracteristicas tem um aluno de EaD de acordo com a reportagem, e relacione-as aos Mitos sobre EaD, que estào no tópico 3 desta aula.

2. A partir do que você fez no item 1 deste fórum, e das informações a respeito do público-alvo do Curso de Especialização em Orientação e Mobilidade, trace um perfil do atuno para quem vocé vai escrever o material didático (por exemplo: idade, escolaridade, motivaçào para fazer o curso, tempo de dedicaçào ao curso, expectativa em relaçào ao novo aprendizado, grau de interesse pelas tarefas do curso, possiveis razòes de evasào, grau de proficiência em leitura e escrita, entre outras caracteristicas). Lembre que algumas caracteristicas vocè deverá supor. Sugerimos que você confira o documento 'Projeto do curso', na Biblioteca, para obter maiores detalhes e realizar essa atividade.

3. A partir do que você estudou nesta aula e das inquietações / convicçòes / dúvidas que você tem sobre EaD, trace o perfil adequado para um professor de EaD. Pense também nas suas caracteristicas como professor conteudista e possivel professor formador.

Organize seu texto por tópicos, para que fique mais fácil os colegas e o tutor fazerem comentários em relação a sua resposta. Nảo esqueça de comentar as respostas dos colegas!

Média das avaliações: -

Editar | Responder

Figura 1 - Fórum da aula 1 do curso de formação de Professores-autores do Curso de Pós-Graduação em OM.

Como se observa, o fórum abrange toda a aula e tem como principal objetivo discutir o perfil do aluno ao qual os cursistas deverão escrever os conteúdos do curso de $\mathrm{OM}$ e deles mesmos, enquanto professores-autores. Em consequência disso, o professorautor reflete também para a escrita didática, que deve ser voltada para o outro. Vejamos agora interações no fórum:

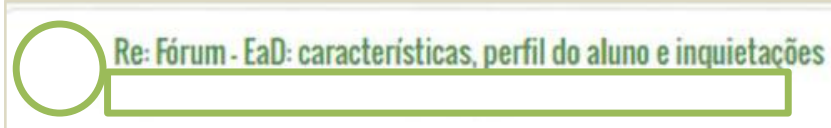

1. $O$ aluno đa EAD deve ser mais responsável que o aluno da educaçào presencial. Deve organizar seus horários, participar das atividades do ambiente e estudar os materiais propostos, bem como buscar novas fontes. Isso exige uma organizaçào prévia por parte do aluno. Muitas pessoas procuram a EAD por nào terem tempo de participar de aulas presenciais. Essas pessoas estão extremamente enganadas, pois EAD nào significa pouco tempo de dedicaçào. Ao contrário, significa mais tempo de estudo nos lugares e horários que o atuno deseja. A EAD presa pela responsabilidade e a autonomia do aluno.

2. O público alvo para o curso de especializaçào em orientaçào e mobilidade será formado por alunos de no minimo 22 anos de idade, graduados em licenciaturas diversas e que atuam como professores de pessoas com deficiência visual. Estes alunos da EAD deverào ter tempo para se dedicar ao curso, cumprir com as atividades, estudar os materiais propostos, buscar novas fontes e interagir com tutores, formadores e com a turma. 3. O professor da EAD Deverá ser responsável com os horários, criativo ao elaborar fóruns, motivador com a turma, ter disponibilidade de horário para atender os alunos em suas đúvidas, propor atividades que despertem interesses dos alunos, motivar a participaçào dos alunos nas atividades, buscar os alunos ausentes, motivando-os a uma participaçào mais ativa e propor chats e fóruns que alimentem os debates entre a turma.

Figura 2 - Interação de cursista (professor-autor) no fórum da aula 1.

A partir das interações mostradas nas figuras 1 e 2 , vê-se que os cursistas perceberam a importância de se considerar o perfil e as necessidades do aluno que estuda a distância, que precisa ter meios, materiais e estratégias didáticas concebidas para que 
sua aprendizagem seja facilitada e ocorra na interação, colaboração e desenvolvimento de sua autonomia. Além disso, refletiram sobre o papel do professor de $\mathrm{EaD}$, em especial, o conteudista, que deve promover a construção do conhecimento através de textos didáticos adequados a essa modalidade de ensino.

Nesta primeira aula, refletiu-se também sobre como EaD e a educação presencial apresentam semelhanças e diferenças no que diz respeito à interação aluno-aluno, alunoprofessor e aluno-conteúdo. O que vai marcar a diferença específica entre cada modalidade é o estabelecimento dos objetivos de ensino, a metodologia e os recursos didáticos utilizados. As opiniões sobre semelhanças e diferenças, ou ainda sobre uma suposta oposição entre as duas modalidades, gera bastante controvérsia. Maia e Mattar (2007, p. 70-71), por exemplo, discutem o papel do professor e do aluno em EaD. Segundo os autores, esse papel seria o mesmo do ensino presencial tradicional.

Como forma de estimular o uso e a aplicação dos recursos multimodais disponíveis no Ambiente Virtual de Aprendizagem por parte dos professores-autores alunos do curso de formação, foi-lhes sugerido um vídeo (http://www.youtube.com/watch?v=08rVXi55yjE) em que o filósofo contemporâneo Pierre Lévy fala acerca de suas expectativas sobre educação a distância. A aula 1 termina anunciando que o processo de planejamento do material e a distribuição dos conteúdos em aulas e tópicos, bem como as fases de produção na equipe de produção do material didático seriam estudados na aula 2.

Alguns sujeitos intervêm com estratégias que marcam seu estilo, sua visão de mundo, sua argumentatividade que tanto os individualiza como cria fronteiras entre eles; outros se orientam pelas marcas de estilo e pela argumentação empreendida pelo sujeito que se sobressai no jogo discursivo; outros pelas peculiaridades do próprio gênero. É, porém, graças ao gênero discursivo que está sendo produzido e suas características que posturas podem ser contestadas, uma vez que uma produção colaborativa e seu contexto discursivo exigem dos sujeitos determinadas tomadas de decisão em torno de orientação temática de sentido com toda sua carga de expressividade e suas relações com os outros enunciados.

\subsection{A Produção do conteúdo didático digital em EaD}

A questão da autoria do material didático digital envolve etapas recursivas, cujos sujeitos interagem de forma diferente entre si e manipulam o texto a partir de uma competência discursiva a qual lhe é atribuída no processo de produção colaborativa. Todavia, tanto a manipulação do texto nas etapas recursivas quanto a atribuição da competência de cada sujeito é influenciada pela hierarquia previamente estabelecida entre os sujeitos que produzem colaborativamente. Essa hierarquia tem como foco garantir a marca de estilo dos sujeitos e a autoria do texto em estreita relação com a ideia de resposta-responsável definida por Bakhtin (1997) e a ideia de peso entre os enunciatários percebida por Sobral (2009).

$\mathrm{Na}$ aula 2 do curso de formação, que tinha como título "Planejamento: fases da produção do conteúdo didático-digital", discutimos que a organização do conteúdo deve apresentar uma visão direcionada para a educação e principalmente para a comunicação. Portanto, era importante que as atividades que seriam produzidas estivessem voltadas 
para a aprendizagem do adulto e que tivessem relação com a reflexão e a ação dele. Os professores-autores deveriam saber que - no caso específico do Curso de pós-graduação em Orientação e Mobilidade - OM, na modalidade semipresencial para o qual produziriam material -, no planejamento e na produção do material didático de cada disciplina, deveria ficar claro que o aprendizado de cada conteúdo seria necessário ao aluno do curso de OM.

Nesta aula, os professores autores viram que a fase de desenvolvimento é a culminância do processo de planejamento e que, nessa etapa, é traçada a previsão das atividades de ensino que se converterão no plano didático propriamente dito, que é composto pela seleção e organização do conteúdo, definição dos recursos e materiais didáticos, estratégias de ensino e pela avaliação. Sendo assim, viram que, para a elaboração do planejamento, é necessário que cuidados sejam tomados em relação alguns aspectos, como a definição de objetivos da disciplina; a delimitação do conteúdo; os materiais a serem utilizados; e o uso da tecnologia.

O autor de referência nesta aula foi Asinsten (2007). Ele explica que há quatro possibilidades de criação/utilização de web-aulas no AVA: 1. utilizam-se materiais que não foram criados especificamente para a $\mathrm{EaD}$ (esse material tal e qual figura no modelo impresso é transferido para o ambiente virtual de aprendizagem; 2 . adaptam-se para o AVA materiais didáticos que não foram criados especificamente para EaD; 3. utiliza-se como web-aula material originalmente criado para $\mathrm{EaD}$, porém que foi produzido por outra instituição de ensino que não aquela em que é usado o material; e 4. elabora-se o próprio material didático pela instituição em que será utilizado. A diferença principal entre as possibilidades de criação descritas por Asinsten nos pontos 3 e 4 está no fato de que, se uma instituição recebe material didático-digital feito por outra instituição para trabalhar com os alunos em $\mathrm{EaD}$, torna-se mais difícil para a instituição que recebe o material fazer reajustes e discutir aspectos como conteúdo, interatividade e adequação ao contexto situacional de aprendizagem. Em nosso contexto de pesquisa, a formação acontece porque o material didático-digital em formato de web-aula é produzido pela própria instituição (no caso, IFCE) que irá utilizá-lo nos cursos de EaD.

Nesta terceira web-aula, os professores-autores refletiram também sobre como seria a disciplina cujo material didático-digital elaborariam. Escreveram e reescreveram o planejamento e praticaram uma das etapas da própria tarefa de escrever, a de planejar o que será dito, como será dito e para que será dito. Foi montada uma espécie de oficina de planejamento e, ao final, eles deveriam elaborar uma guia didática que apresentasse a estrutura geral do material didático-digital que escreveriam, com nome dos títulos, previsão dos objetivos de aprendizagem por parte dos alunos, esboço do conteúdo informacional e dos subtítulos de cada seção temática. Também nesta guia didática foi feita uma equivalência da carga-horária de cada material que seria elaborado com a quantidade de páginas (para material didático-digital) e frames (para a web-aula). Com a entrega da guia didática, finalizou-se a segunda aula do curso de formação de professoresautores.

\subsection{Textualização didática: bases iniciais}

$\mathrm{Na}$ terceira aula do curso, Produção de conteúdo I, foram discutidas 
primeiramente as características da tarefa de escrita, relacionando-a com a tarefa de escrever textos didáticos assumida pelo professor-autor em $\mathrm{EaD}$. Na segunda parte da aula, apresentou-se a estrutura do material didático impresso destinado à EaD no IFCE.

O objetivo da aula 3 foi facilitar o processo de produção escrita e sugerir caminhos para a elaboração de um material didático eficiente e adequado para o curso de Especialização em que os professores-autores iriam atuar. Os objetivos gerais da aula foram conhecer as características da tarefa de escrita, bem como a estrutura do material didático voltado para a educação a distância no IFCE. Ela foi dividida em dois tópicos: 1. Escrever para o outro, cujos objetivos foram diferenciar texto didático de texto científico e conhecer características da escrita em EaD (BAKHTIN, 2011; CHEVALLARD, 1991); e 2. Estrutura do material didático do IFCE, com o objetivo de fazer os professores do curso de formação conhecerem os aspectos da escrita dos textos que compõem o material didático destinado à EaD no IFCE.

Com base em Chevallard (1991) e na teoria da transposição didática, os professores do curso de formação estudaram que os saberes (sábio e ensinado) sofrem duas transformações: uma quando o saber sábio (gerado no âmbito científico) se converte em saber a ensinar (visto em contextos de programas curriculares); e outra quando esse saber a ensinar é levado à aula, isto é, quando se transforma em saber ensinado. Eles também compreenderam que o processo de publicização do saber passam por um alinhamento didático que transpõe o saber para o texto. A esse alinhamento didático Chevallard chama de textualização. Para o autor, a textualização didática do saber pressupõe uma progressão do conhecimento, o que significa que o texto terá um começo, um meio e um fim. Segundo ele, a textualização didática objetiva justamente a publicização do saber a ensinar, a fim de que esse saber seja público em oposição ao caráter "privado" dos saberes sábios. Essa publicização, por sua vez, "permite o controle social dos aprendizes, em virtude de uma certa concepção do que é o saber, concepção fundada (ou legitimada) pela textualização" (op. cit., p. 62).

$\mathrm{Na}$ terceira parte da aula 3, abordou-se a escrita em EaD, mais especificamente a escrita de material didático. Viu-se que ela apresenta características específicas se comparada à escrita didática comum porque os usos da linguagem verbal em $\mathrm{EaD}$, em boa medida, compensam a ausência de interação face a face típica da modalidade presencial.

No que se refere às atividades discursivas identificadas na escrita do material didático-digital e sua relação com a transposição didática, os professores autores viram que não só apenas conhecimentos linguísticos são demandados ao produtor do texto, mas aspectos cognitivos e interacionais que dizem respeito a estratégias usadas pelo produtor do texto. Com base em Koch e Elias (2009), elencam-se, na web-aula 3 do curso de formação de autores, estratégias ativação de conhecimentos sobre os componentes da situação comunicativa, como os interlocutores (alunos que estudam em $\mathrm{EaD}$ ), o tópico a ser desenvolvido (tema principal da disciplina e subtemas que dele decorrem) e a configuração adequada à interação em foco (livro impresso, livro digital, outros materiais didáticos digitais, como o gênero web-aula).

Foram estudadas algumas das principais características da escrita em $\mathrm{EaD}$, tais como a) tom dialogal, estabelecido entre professor-autor e aluno por intermédio do texto; 
b) constante reflexão sobre o conteúdo, reflexão dirigida que reproduz em boa medida o que fazemos na interação face a face na sala de aula presencial; c) críticas ao saber sábio que esteja desatualizado, críticas a pontos de vista já superados pela ciência como característica de todo texto didático e também dos textos destinados à $\mathrm{EaD}$; d) exemplos práticos baseados no cotidiano, que facilitam a compreensão pelo aluno e podem tornar a aprendizagem mais concreta; e) utilização de linguagem não verbal, uso de mais de uma semiose: verbal e não-verbal.

Com estas características, finalizou-se a aula 3. Nela os professores refletiram com mais profundidade sobre a escrita de material didático destinado à $\mathrm{EaD}$ e sobre a estrutura do material impresso do IFCE. Na aula 4, última aula do curso de formação, foi tratado do material didático-digital, com destaque especial à estrutura multimodal da web-aula.

\subsection{Textualização didática: fechamento da produção didática}

$\mathrm{Na}$ última aula, quarta web-aula, em seu primeiro tópico temático da web-aula, os professores-autores conheceram o fluxograma completo da equipe de produção da qual fariam parte e observaram as funções/tarefas de cada membro da equipe multidisciplinar de produção. Assim, esse tópico trouxe importantes informações sobre o funcionamento da equipe multidisciplinar e, principalmente, sobre o desenvolvimento da escrita colaborativa que caracteriza a produção de material didático na $\mathrm{DEaD/IFCE}$.

Com base em Araújo et al. (2014), os alunos aprenderem que a web-aula transita entre a aula presencial (feita a devida transposição didática) e o material didático impresso (como uma unidade do livro didático, por exemplo). Na web-aula 4, os professores viram que, à semelhança de outros gêneros do domínio digital, uma das características da webaula seria a hipertextualidade. Essa característica se dá em função do medium em que a web-aula se insere: a rede www. Dessa forma, o simples fato de a web-aula funcionar em um novo meio, a rede www, já lhe confere de antemão características que são típicas da própria rede. Entre esses atributos, estaria a possibilidade de navegação por meio de hiperlinks, que levariam o leitor para outros textos, fora do texto principal da aula virtual.

Ainda segundo Araújo et al. (op. cit.), os professores viram que outra característica também decorrente do meio em que circula a web-aula seria a multimodalidade. Esta característica, neste caso, deveria ser muito mais acentuada do que numa aula da modalidade presencial. Assim, no caso da web-aula, tem-se um gênero composto de textos multimodais (o próprio texto escrito principal que, por meio de links ou de inserções no próprio corpo do texto, apresenta também, por exemplo, imagens estáticas ou em movimento, sons, etc.) e de outros gêneros típicos da modalidade $\mathrm{EaD}$, tais como fóruns, listas de discussão, wikis, chats educacionais, entre outros.

No segundo tópico da web-aula 4, descreveram-se os recursos multimodais e hipertextuais que poderiam ser utilizados no processo de retextualização do texto da aula em versão impressa em web-aulas. A utilização desses recursos depende do tipo de conteúdo informacional que se quer desenvolver e da função que ele cumprirá no material didático. Os recursos estudados nesta aula foram: ícones, links, objetos de aprendizagem, imagens, animações, entre outros. O objetivo principal da web-aula 4 era oferecer um norte no que se refere aos tipos de recursos multimodais e hipertextuais, aos conteúdos e 
materiais de apoio para a pesquisa e leitura, etc. que poderiam ser explorados pelo professor-autor na produção do material didático.

Para finalizar a última web-aula do curso de formação, enfatizou-se a importância do gênero web-aula. Tomou como referência o texto de Asinsten et al. (2012). Nele os autores afirmam que a web-aula é fundamental para o modelo pedagógico de ensinoaprendizagem no contexto de Educação a Distância. Esses autores apresentam uma definição de web-aula (ou aula virtual) como conjugação daquilo que se pode resgatar dos formatos e das práticas docentes da aula presencial com as concepções que tendem a centrar muito mais a aprendizagem na própria atividade dos alunos com a incorporação das novas possibilidades de gestão do conhecimento que oferecem os meios digitais. Dessa forma, a web-aula tenta reproduzir, nos ambientes virtuais de aprendizagem, aquilo que o docente faz na aula presencial, ou seja, quem produz este gênero tenta explicar, ampliar, exemplificar a fim de ajudar a compreensão dos alunos dos conceitos discutidos, a fim de que eles aprendam.

Os professores do curso de formação de autores de material didático-digital para o curso de Especialização em Orientação e Mobilidade compreenderam que a web-aula funciona, no modelo de $\mathrm{EaD}$, como um organizador, um centralizador do curso, dos materiais e dos recursos multimodais e hipertextuais utilizados no processo formativo. Perceberam particularmente que, dentre as características do gênero web-aula, uma em especial tem bastante relevância para este estudo. Trata-se do modo de produção desse gênero, cuja colaboração entre sujeitos especializados é a base do processo de escrita.

Com base no fluxograma de produção de material didático-digital que estudaram na web-aula 3 da formação, os professores viram que escrita colaborativa se trata de um processo de produção textual que se dá a partir da colaboração de diferentes sujeitos que juntos produzem o mesmo texto. Esses sujeitos cooperam na produção escrita por meio de estratégias de interação (recados escritos, discussão presencial, revisões e correções no texto, etc.) com intuito de construir colaborativamente o texto.

Com isso, findaram-se as quatro principais temáticas aludidas nas quatro webaulas do curso de formação de professores-autores. Na próxima seção, descreveremos como se deram os encontros presenciais e como foi feita a adaptação das web-aulas para os professores com deficiência visual que foram convidados para serem autores de material didático-digital para o curso de Especialização e Mobilidade do IFCE.

\section{Processos de autoria na produção de material didático digital}

Foram realizados dois encontros presenciais de $4 \mathrm{~h} / \mathrm{a}$ cada no curso de formação de professores-autores de material didático-digital para a Educação a Distância (EaD), além das web-aulas e discussões no Ambiente Virtual de Aprendizagem (AVA). O primeiro encontro teve como objetivos apresentar a estrutura geral do curso de formação e introduzir a temática de produção de materiais didáticos para $\mathrm{EaD}$ nos moldes adotados pela Diretoria de Educação a Distância do IFCE (DEaD-IFCE). Já o segundo teve as propostas de refletir sobre a Linguagem em $\mathrm{EaD}$ e discutir sobre os direitos relativos à autoria. 
No primeiro encontro, foram estudados os conceitos, características e modelos de $\mathrm{EaD}$, apresentadas as competências linguísticas necessárias para a elaboração de materiais didáticos impressos e digitais para a modalidade de ensino a distância, como as competências na produção de texto verbais (conteúdos textuais) e não verbais (imagens, figuras, ícones e vídeos); estrutura do materiais didáticos do modelo adotados; as etapas de produção e a equipes multidisciplinares que estão envolvidas em todo o processo de elaboração do material didático.

No segundo encontro, dividido em dois períodos, foram apresentados respectivamente o estudo da Linguagem em $\mathrm{EaD}$ e as leis da propriedade intelectual com foco na Lei de Direitos Autorais (Lei 9610/98) e os tipos de licenças Creative Commons (CC). Durante esse segundo momento, foram feitas análises de casos de uso de obras de terceiros, como imagens, textos, músicas e vídeos. Os cursistas precisavam, em grupo, ler alguns casos hipotéticos. Um dos casos hipotéticos apresentados para os professores foi "sou professora de História e adoro fazer videoaulas sobre os conteúdos que ensino. Em um dos meus vídeos, coloquei, como música de fundo, a $9^{\text {a }}$ Sinfonia de Beethoven, gravada pela Som Livre e executada pela Orquestra Petrobras em 2011”.

Eles deveriam analisar e julgar se o uso das obras era correto ou incorreto. $\mathrm{O}$ objetivo da discussão sobre as leis relativas à autoria era conscientizar os futuros professores-autores sobre a importância do uso correto de obras de terceiros, evitando assim possíveis casos de plágios ou "roubo intelectual" e deixar claros os direitos deles em relação as suas futuras obras.

Depois discutiu-se sobre a escrita colaborativa. Com base em Sanchéz (2009), refletiu-se que os sujeitos participantes do processo devem compartilhar a responsabilidade de produção do texto, no que se refere à estrutura (multimodal e hipertextual), ao conteúdo (da disciplina) e à linguagem (dialogal). Foi salientado que uma escrita colaborativa vai mais além de uma revisão entre pares (atividade bastante comum quando se trata de estudos sobre escrita colaborativa), pois favorece o pensamento reflexivo (sobretudo se os participantes usam estratégias para defender ou explicar melhor suas ideias); a abordagem de questões relativas ao discurso (e não apenas à materialidade do texto em seus aspectos formais, por exemplo); e o desenvolvimento da linguagem.

No segundo encontro presencial, foi enfatizado que, para haver tais implicações (pensamento reflexivo, questões relativas ao discurso e desenvolvimento da linguagem) no processo de escrita colaborativa, é necessário identificar as estratégias de comunicação e coordenação que se supõe haver no trabalho entre os sujeitos, já que a escrita colaborativa é dependente de comunicação (SANCHÉZ, 2009). Essas estratégias são postas em prática quando os sujeitos trocam informações ao responder as demandas do processo de escrita, cada qual utilizando a competência comunicativa necessária em um dado momento do processo de escrita. Nessa perspectiva, essas respostas trazem em si um caráter argumentativo.

No caso da web-aula, por exemplo, há entre os professores-autores participantes uma negociação de sentidos do texto e uma necessidade de se chegar a acordos no que diz respeito ao conteúdo, à forma e à organização do próprio texto, bem como aos recursos multissemióticos utilizados na web-aula. Todos esses aspectos devem ser bem orquestrados para que a web-aula se realize como texto adequado, levando-se em conta 
os aspectos textuais e discursivos que a compõem.

No que se refere às competências comunicativas dos interlocutores, elas são importantes para determinar a ativa posição responsiva dos sujeitos que participam de uma produção colaborativa-digital de um gênero como a web-aula. Se cada um deles contribuirá discursivamente para a produção do gênero, a fỉm de torná-lo um enunciado pleno, a competência discursiva de cada um mobilizará princípios de responsividade que caracterizam a web-aula como gênero de escrita colaborativa. Dessa forma, há estratégias discursivas implicadas em cada competência, a cada posição ativa dos sujeitos que dá identidade ao gênero, e em cada escolha dos recursos lexicais, gramaticais e composicionais do enunciado nos gêneros. Essas estratégias têm de ser indiferentes à alternância de sujeitos-participantes no texto, pois são elas que, a partir do gênero, irão caracterizar o enunciado como unidade autêntica da comunicação discursiva em um determinado contexto, que, no caso em tela, é didático, acadêmico e digital.

No caso de um gênero didático-digital como a web-aula, no processo de escrita colaborativo, as estratégias discursivas utilizadas por cada sujeito representam o jogo dialógico e participativo no qual cada um disputa terreno com os outros interlocutores em campo. Essa disputa muitas vezes não é igual, em decorrência da forma como cada um dos sujeitos intervém no texto. Assim, mesmo que a atividade de composição escrita da web-aula permita que um coletivo colabore na produção do gênero, haverá graus diferentes de participação e de responsabilidade sobre o texto.

No próximo tópico, veremos como foram feitas as adaptações no material do curso de formação de professores-autores de material didático-digital para o curso de Orientação e Mobilidade na modalidade a distância. As adaptações nas web-aulas produzidas pela equipe multidisciplinar do IFCE tiveram como norte os parâmetros da acessibilidade para atender à demanda de docentes que tinha deficiência visual (5 professores que participaram do curso de formação eram cegos).

\section{Ferramentas de acessibilidade}

A necessidade de atender a um público específico fez com que a equipe de produção do curso de formação voltasse sua atenção para o acesso aos conteúdos e informações disponíveis no curso e na plataforma como um todo pelas pessoas com deficiência visual. Vimos que era necessário solucionar os problemas de adaptação do material para promover a interação dos alunos com o material na formação docente. Para isso, estabelecemos critérios didáticos no material para criar novos parâmetros de atuação dos docentes com deficiência visual no curso de formação de professores autores. A adaptação teve como diretrizes a criação de alternativas ao conteúdo sonoro e visual, como a ferramentas de leitura de áudio, a estruturação de ordem lógica do conteúdo, para que o aluno identifique as partes principais do material e saiba compreendê-lo de forma adequada e segura.

O primeiro passo foi conferir como os padrões de acessibilidade para a web, 
estabelecidos pela WCAG $1.0^{4}$, estavam sendo aplicados nas web-aulas que os cursistas com cegueira teriam acesso. Para tanto, foi feito um teste com dois usuários cegos, sendo um deles um aluno do próprio curso. Como resultado foi verificado que as web-aulas possuíam as principais funções de navegação utilizadas pelos leitores de tela, como DOSVOX. Entre essas funções analisadas, podemos citar a possibilidade do uso do parâmetro Alt para a descrição de imagens e ícones; a separação entre o conteúdo e o estilo $^{5}$; a dispensa do uso de FRAMES OR CSS equivalente; e a não inserção de CSS ou JS dentro do código.

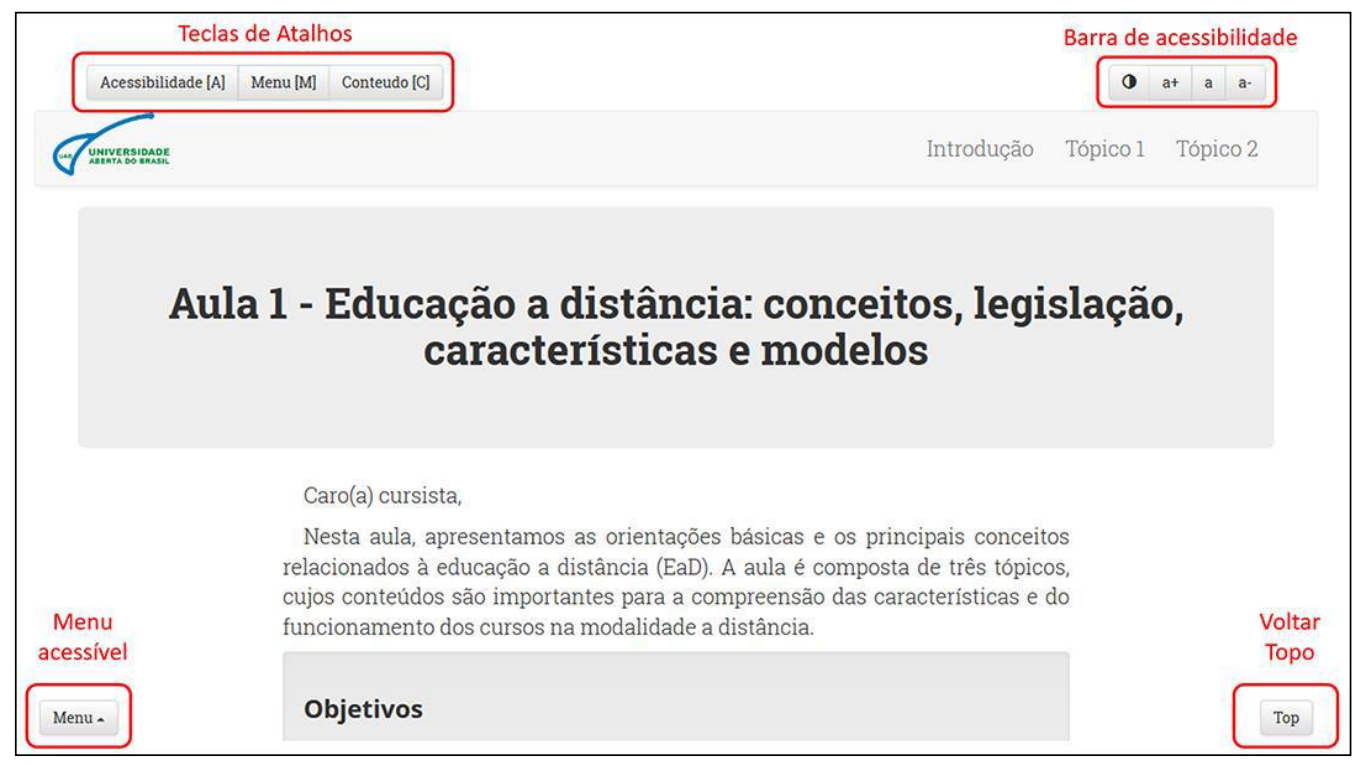

Figura 4 - Novo modelo de web-aula (visualização dos usuários).

Nesse novo modelo, que será utilizado pelos alunos do curso Especialização em OM e pelos próprios professores-autores, que serão professores do curso, percebe-se uma barra de acessibilidade e um menu com teclas de atalhos no topo da página, o que permite aos usuários com deficiência (visual e física) um rápido acesso às funcionalidades principais ao navegar pela página usando o atalho Tab do teclado. Há também a presença de um menu, no canto inferior esquerdo da página, e um botão "Top" (que leva o usuário para o início do conteúdo) no canto inferior direto, que é acessível pelo atalho Tab.

As teclas de atalhos, "Acessibilidade", "Menu" e "Conteúdo", no canto superior direito, permitem que o usuário navegue pela página usando apenas três teclas do teclado: "A", "M" e "C". Já a barra de acessibilidade apresenta funções, como alto contraste (figura 5) e possibilidade de aumentar e diminuir a fonte do texto para pessoas com baixa visão ou visão subnormal.

\footnotetext{
${ }^{4}$ https://www.w3.org/TR/WCAG10/checkpoint-list.html.

${ }_{5}^{5}$ Foi disponibilizada uma página web mais legível, com o CSS desativado, sem uso de cores na estrutura e nas funcionalidades dela. Fez-se uso do HTML estruturado semântico, como h1-h6 para títulos, e do CSS Box Model no lugar de tabelas para o Layout da página.
} 


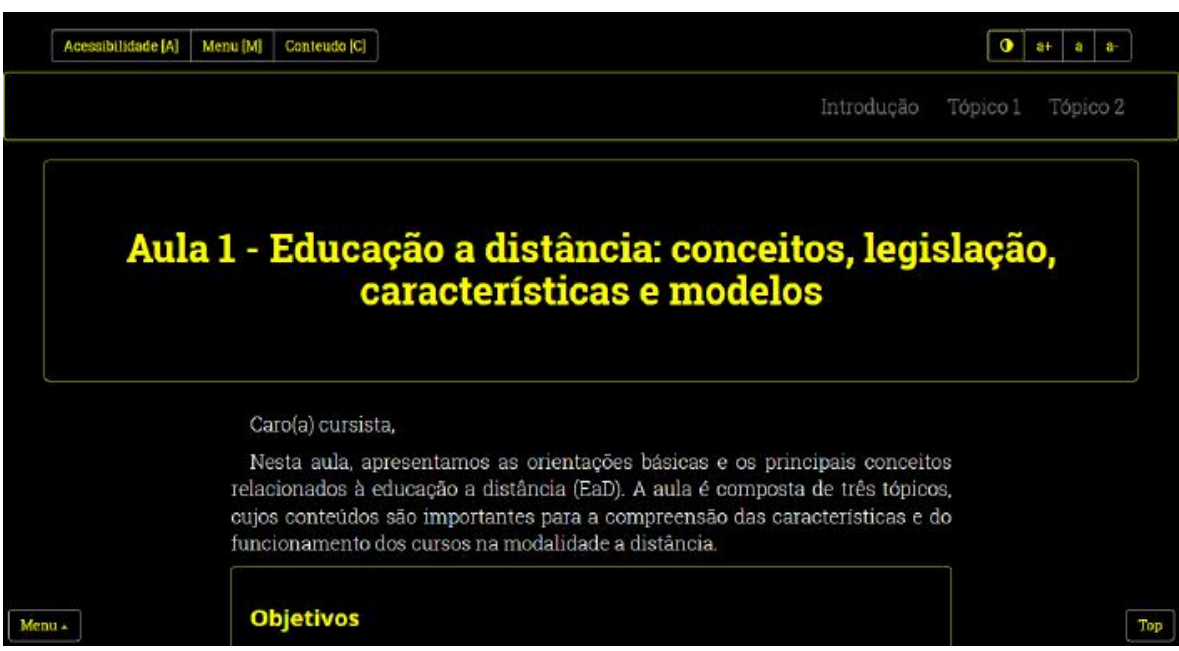

Figura 5 - Nova modelo de web-aula com contraste ativado.

Não somente os conteúdos das web-aulas foram adaptados para se tornarem acessíveis, mas todo o conteúdo apresentando nos dois encontros presenciais foi checado quanto à acessibilidade, utilizando a ferramenta "verificar acessibilidade", indo na opção Arquivo > Informações > Verificando Problemas > Verificar Acessibilidade, no programa PowerPoint, como mostra a figura 6.

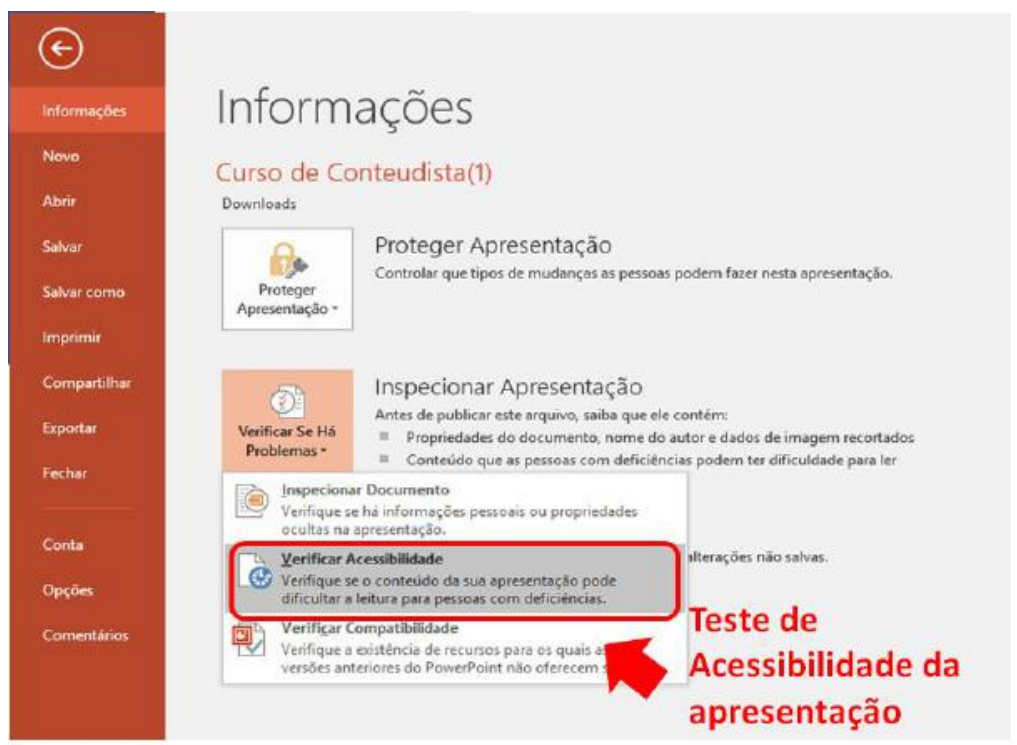

Figura 6 - Teste de acessibilidade do PowerPoint.

As apresentações em slides foram construídas levando-se em conta a navegação entre as informações no slide e entre slides, para que, ao utilizar o leitor de tela, os cursistas cegos possam ter acesso às informações na ordem correta de leitura. Para verificar os elementos, como quadros, texto, tabelas e gráficos (ordenados de forma lógica), é preciso, na aba "Início", escolher a opção "Organizar" e "Painel de Seleção", e verificar a hierarquia dos elementos (figura 7). 


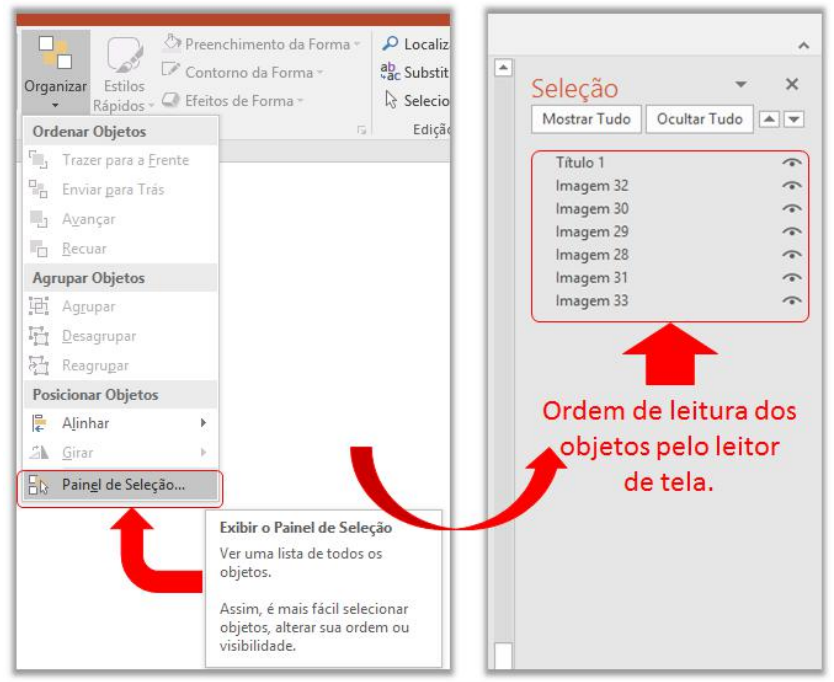

Figura 7 - Verificação da hierarquia das informações apresentadas em um slide.

Houve o cuidado tanto na elaboração de tabelas, para que as informações presentes nelas fizessem sentido quando lidas horizontalmente, como na elaboração de gráficos, para que não se utilizassem cores ou imagens como meio para transmissão de informações importantes. Neste processo de adaptação do material didático-digital para o curso de formação de professores com deficiência visual, fizemos a combinação das percepções táteis e sensoriais, ou seja, a percepção do conteúdo didático obtido através dos recursos acessíveis para evitar a receptividade passiva e converter os alunos em sujeitos no decorrer do curso de formação. Assim, criamos um entorno virtual com esquemas e cenários adaptativos acessíveis fazem os docentes com deficiência visual ficarem imersos no processo de ensino-aprendizagem.

\section{Considerações finais}

$\mathrm{Na} \mathrm{EaD}$, em alguns modelos de cursos adotados, o professor não está fisicamente presente na maior parte do tempo, é o que acontece em cursos semipresenciais. Assim, os materiais didático-digitais, estejam eles disponibilizados nas mídias impressa ou digital, são de grande importância, pois são um dos elementos responsáveis por amenizar a sensação de distância nas relações entre aluno, professor e conteúdo. Nesse sentido, antes de se iniciar a produção de conteúdos, faz-se necessário que os autores/elaboradores passem por uma formação para que possam produzir materiais que assumam forma e conteúdo que se ajustem à concepção pedagógica do curso. Essa formação deve atender ao propósito de formar professores que sejam autores de material didático-digital para a EaD. Em nosso caso, a formação deveria atender professores que lidam com recurso e ferramentas de acessibilidade no seu dia a dia, porém não tinham experiência com ferramentas de inclusão em web-aulas.

O diferencial do curso de formação de professor-autor de materiais didáticodigitais para o Curso de Pós-graduação em Orientação e Mobilidade estava no fato de atende às necessidades específicas de acesso dos professores com deficiência visual à plataforma Moodle, aos conteúdos elaborados e às informações e comunicados do curso; 
além de proporcionarmos familiaridade de todos os professores no uso de ferramentas digitais de comunicação e informação e capacitá-los para a produção escrita (que pode ser multimodal e hipertextual), fazendo uso, assim, da confluência de diversas mídias, na busca de atender aos diferentes estilos de aprendizagem dos alunos que aprendem a distância.

Dessa forma, consideramos que o modelo aplicado no IFCE com as ferramentas de acessibilidade usadas nas 4 web-aulas do curso de formação e as temáticas trabalhadas podem ser replicado em outras instituições, uma vez que são bastante didáticas do ponto de vista da forma como foram divididas as aulas, apresenta conteúdo objetivo e permite aos professores-autores aprender a escrever, escrevendo, em um movimento de escrita colaborativa de que participam vários atores com diferentes habilidades e estratégias de aprendizagem.

\section{Referências}

ALMENARA, J.C. Las Web para la formación. In: SALINAS; AGUADED; CABERO (Coords). Tecnologías para la Educación: diseño, producción y evaluación de medias para la formación docente. 5a . ed. Madrid: Alianza Editorial, 2011.

ARAÚJO. N.; HISSA. D.; ZAVAM; A. Material didático em EaD: a produção de uma web-aula. Em: ROCHA, et al. Material Didático na EaD: caminhos de autoria. Dourados, MS: UEMS, 2014.

ASINSTEN, J.C. et al. Construyendo la clase virtual: métodos, estrategias y recursos tecnológicos para buenas prácticas docentes. Buenos Aires: Centro de Publicaciones Educativas y Material Didáctico, 2012.

ASINSTEN, J.C. Producción de contenidos para Educación Virtual. Biblioteca Virtual Educa. Publicación en línea, 2007.

BAKHTIN, M. Estética da criação verbal. São Paulo: Martins Fontes, 2011.

BRASIL. Legislação Brasileira sobre pessoas com deficiência [recurso eletrônico]. $7^{\text {a }}$. ed. Brasília: Câmara dos Deputados; Edições Câmara, 2013.

CHEVALLARD, Y. La Transposition Didactique: du savoir savant au savoir ensigné. Grenoble: La Pensée Sauvage, 1991.

GUEDES, J. Produção de material didático para EaD no Curso de Licenciatura em Matemática: o caso da UAB/IFCE. Dissertação. Mestrado em Educação, Universidade Federal do Ceará, Programa de Pós-graduação em Educação Brasileira, Fortaleza, 2010.

KOCH, I.V.; ELIAS, M.V. Ler e escrever: estratégias de produção textual. São Paulo: Contexto, 2009.

MURRAY, D.E. Collaborative writing as a literacy event: implications for ESL 
instruction. In: NUNAN, David (Org.): Collaborative Language Learning and Teaching. Cambridge: CUP, 1992.

RODRÍGUEZ DA LAS HERAS. El tercer espacio. Madrid, 2002. Disponível em rodriguezdelasheras.es. Acesso em 20 de abr. de 2017.

SÁNCHEZ, A.B. Escritura colaborativa en línea un estudio preliminar orientado al análisis del proceso de co-autoría. Revista Iberoamericana de Educación a Distancia [RIED], vol. 12, n. 2, 33-55, 2009. Disponível em https://dialnet.unirioja.es/servlet/articulo?codigo=3277826. Acesso em 9 mar. 2017.

SOBRAL. A. Do Dialogismo ao Gênero: as bases do pensamento do círculo de Bakhtin. Campinas: Mercado da Letras, 2009.

SPIVEY, N.N. The constructivist metaphor: reading, writing, and the making of meaning. Emerald Group Pub Limited, 1997.

Artigo recebido em: julho de 2017.

Aprovado e revisado em: outubro de 2017.

Publicado em: novembro de 2017.

\section{Para citar este texto:}

HISSA, Débora Liberato Arruda. Acessibilidade na formação de professores-autores de material didático-digital para a $\mathrm{EaD}$ : um trabalho com deficientes visuais. Entremeios [Revista de Estudos do Discurso, on-line, www.entremeios.inf.br], Seção Temática [Linguagem e Tecnologia], Programa de Pós-Graduação em Ciências da Linguagem (PPGCL), Universidade do Vale do Sapucaí (UNIVÁS), Pouso Alegre (MG), vol. 15, p. 279-300, jul. - dez. 2017.

DOI: http://dx.doi.org/10.20337/ISSN2179-3514revistaENTREMEIOSvol15pagina279a300 